\title{
Technology, knowledge and markets: connecting the dots-electric rickshaw in India as a case study
}

\author{
Nisha Chandran ${ }^{1}$ and Samir Kumar Brahmachari ${ }^{1,2^{*}}$
}

\begin{abstract}
Innovation is a process of integrated thinking. The interactions between technology, market and the need for technology remain unconnected. Connecting these unconnected dots leads to a market disruption, paving the way for an economically viable innovation. India has various national-level programmes that foster innovation environments for the creation of economic empowerment. This paper looks at one such innovation: the soleckshaw: solar electric rickshaw. The emergence of these electric rickshaws came from enhancing the design of already existing cycle rickshaws to create better rickshaws, which are socially acceptable as they reduce human drudgery and are environment friendly, leaving a low-carbon footprint. The case being highlighted here, that existing knowledge connected with existing technology to address a need, leads to new consumers and new markets and eventually causing a technology-led policy intervention. The paper also looks at the role non-exclusive licencing plays in the absorption and dissemination of an innovation.
\end{abstract}

Keywords: Electric rickshaw, Soleckshaw, Crowdsourcing, Frugal, Low cost, Innovation, Make in India

\section{Background}

The existence of technology, knowledge, market and need does not necessarily translate into an innovation. Innovation is the outcome of integrated thinking. Technological interventions create a new consumer base that is not just socially and economically diverse but also provides for a diverse market to be created. For an innovation to occur, one must be able to connect the existing unconnected dots of technology, market and social need. One of the most talked about ways to achieve higher growth has been through disruptive innovation (Christensen 1997). Technological innovations can be in the form of low quality and low cost, and entering into a market where already a superior technology exists, this creates an environment for disruptive innovation to take place (Yu and Hang 2010). Targeting the lower group of the economic pyramid becomes crucial for social innovation as well as economic development. The capacity to innovate at this level leads to creation of an intermediary domain of social entrepreneurs. With the

\footnotetext{
* Correspondence: skb@igib.res.in

${ }^{1}$ Academy of Scientific and Innovative Research, New Delhi, India

${ }^{2}$ CSIR-Institute of Genomics and Integrative Biology, New Delhi, India
}

concept of micro-financing evolving through the grass roots, the dynamics of social change is associated with creating micro-consumers, micro-producers, microfirms, micro-entrepreneurs and micro-innovators with the capacity to scale up (Prahalad 2005). Developing economies, such as India, prove conducive for disruptive innovation to occur. The low-income-group population combined with a highly mobile economy allows new products to be created (Hang, Chen et al. 2010) and absorbed rapidly into the market. The existence of technologies does not ensure their dissemination uniformly; technology as a social intervention occurs by interlinking technological capacities. Fusing existing technology with new technology has the capability to create a new business model. However, setting the price of the technology to attract a large pool of customers is more important than targeting only mainstream customers (Kim and Mauborgne 1999). The article showcases the role of innovation in the rickshaw industry of India and how a technology-led intervention in the rickshaw market allowed for a new product to uplift rickshaw pullers from poverty while maintaining environmental consciousness.

\section{黑 Springer}

(c) 2015 Chandran and Brahmachari. Open Access This article is distributed under the terms of the Creative Commons Attribution 4.0 International License (http://creativecommons.org/licenses/by/4.0/), which permits unrestricted use, distribution, and reproduction in any medium, provided you give appropriate credit to the original author(s) and the source, provide a link to the Creative Commons license, and indicate if changes were made. 


\section{Relevance and development of the rickshaw in Asia}

The rickshaw derives its name from the Japanese word "jinrikisha", literally translating to human-powered rickshaw. Over the past century, the rickshaw has seen many transformations, from hand-pulled to cycle rickshaws to motor-assisted rickshaws; however, these transformations have been unable to replace the human effort required in operating the rickshaw while maintaining an eco-friendly environment. The earliest known rickshaw was first developed around 1870 in Japan (Rahman, D'Este et al. 2009). Eventually, by the early 20th century, they became a popular mode of transport in most parts of Asia such as China, Singapore, Vietnam, India and Bangladesh. Around 1880, rickshaws appeared in India, first introduced in Simla by Reverend J. Fordyce (Kanwar 2003). At the turn of the century, it was introduced in Calcutta, India, and in 1914 was a conveyance for hire (Jim 2011; Singh, Gambhir et al. 2011). The rickshaw was a mode of easy transport for the elite and also an important actor in facilitating intra-city transport of goods. For a good part of the early 20th century, the conventional rickshaw was still being hand-pulled. By 1929, the cycle rickshaw first appeared in Singapore; though bicycles were becoming more popular during that time, it was only when the prices of bicycles started lowering that the humanpulled rickshaw transitioned into a cycle rickshaw; by 1935, the cycle rickshaw outnumbered the handpulled rickshaw. Cycle rickshaws appeared for the first time in Calcutta, India, starting at about the 1930 s, and by the 1950s, they were present in every country in South and East Asia (Edgerton 2007).

The rise of the cycle rickshaw came as a boon for the rickshaw pullers. It reduced the effort in operating the rickshaws as well as generated more revenue for their services. However, the survival of the cycle rickshaw has been difficult. Growing urbanisation, increase in the number of private vehicles, congestion of roads and increasing population has forced the governments of Asian cities to stop the operations of rickshaws. Currently, in Asia, Dhaka, the capital city of Bangladesh, houses nearly two million rickshaws (Rhaman 2013) while India alone has 10 million rickshaws. China, which saw the banning of hand-pulled rickshaws under the Mao regime, as it was considered a sign of human oppression, recently has seen a rise in motorised rickshaws. In different parts of Asia, differing types of rickshaws exist. Based on the design of operation, these are pulled-type rickshaws (where the rickshaw puller sits in front and the passengers sit behind while the rickshaw puller pedals) mostly found in India and Bangladesh; sidecar-type rickshaws (where the passenger seating is positioned laterally to the rickshaw puller) as found in Thailand (known as Samlor), Myanmar (known as Saikaa) and Philippines; and push-type rickshaws (where the passengers are seated in front while the rickshaw puller is seated behind while he pedals), found in Indonesia (known as Becak),Vietnam, Cambodia (known as Cyclo) and Malaysia (known as trishaw) (Motooka 2008). Figure 1 shows the map of major types of rickshaws distributed across Asia.

The role of the rickshaw is ever evolving in society as dependence on them increases. In Delhi, the capital city of India, the cycle rickshaws not only transport passengers but also act as cargo carriers through the narrow bylanes of the old city, provide metro feeder services, alternates to buses and for plying children to and fro from schools.

Cycle rickshaws also play a crucial role in employment and poverty alleviation in many countries in Asia. In most developing countries, the rickshaw pullers are migrant workers from rural areas looking for employment in urban areas. The lack of proper education and necessary skills makes this migrant population unable to secure an employment in the formal sector, thereby forcing them to become a part of the informal sector workforce. Among the Asian countries, Bangladesh and India have the highest number of rickshaws with Dhaka being known as the Rickshaw Capital of the World. Rickshaws are one of the most important contributors to the Bangladeshi economy; nearly $6 \%$ of Bangladesh's GDP is contributed by rickshaw pullers. Around $20 \%$ of the Bangladeshi population relies directly or indirectly on rickshaw pulling (Rahman, D'Este et al. 2008).

The transition of hand-pulled rickshaws to the cycle rickshaw can in part be attributed to the innovations in the bicycle industry, which allowed cycle rickshaws to emerge and thrive thereby improving the quality of life of a rickshaw puller. However, since the emergence of the cycle rickshaw, little-to-no innovation has taken place in the past 80 years. Technology governing engines, automobiles, fuels, roads, cycles, etc. has evolved tremendously over the years; however, since the 1930s till 2008, little has changed in the function and design of the cycle rickshaw. Human effort in pedalling the rickshaw remained. The seemingly small rickshaw industry of India supports nearly $4 \%$ of India's population (considering each rickshaw puller supports a family of 5); hence, their economic contribution cannot be ignored. Therefore, a lack of innovation in this sector was alarming. The article focuses on how the solar electric rickshaw, a brain child of the then Director General (DG) of the Council of Scientific and Industrial Research (CSIR), was developed by the CSIR-Central Mechanical Engineering Research Institute (CMERI), Durgapur, under his stewardship, utilising the existing technological know-how and connected the dots to disrupt an existing cycle rickshaw market. The primary focus of the initiative being to provide a prototype which would reduce human effort in pedalling a cycle rickshaw, while 


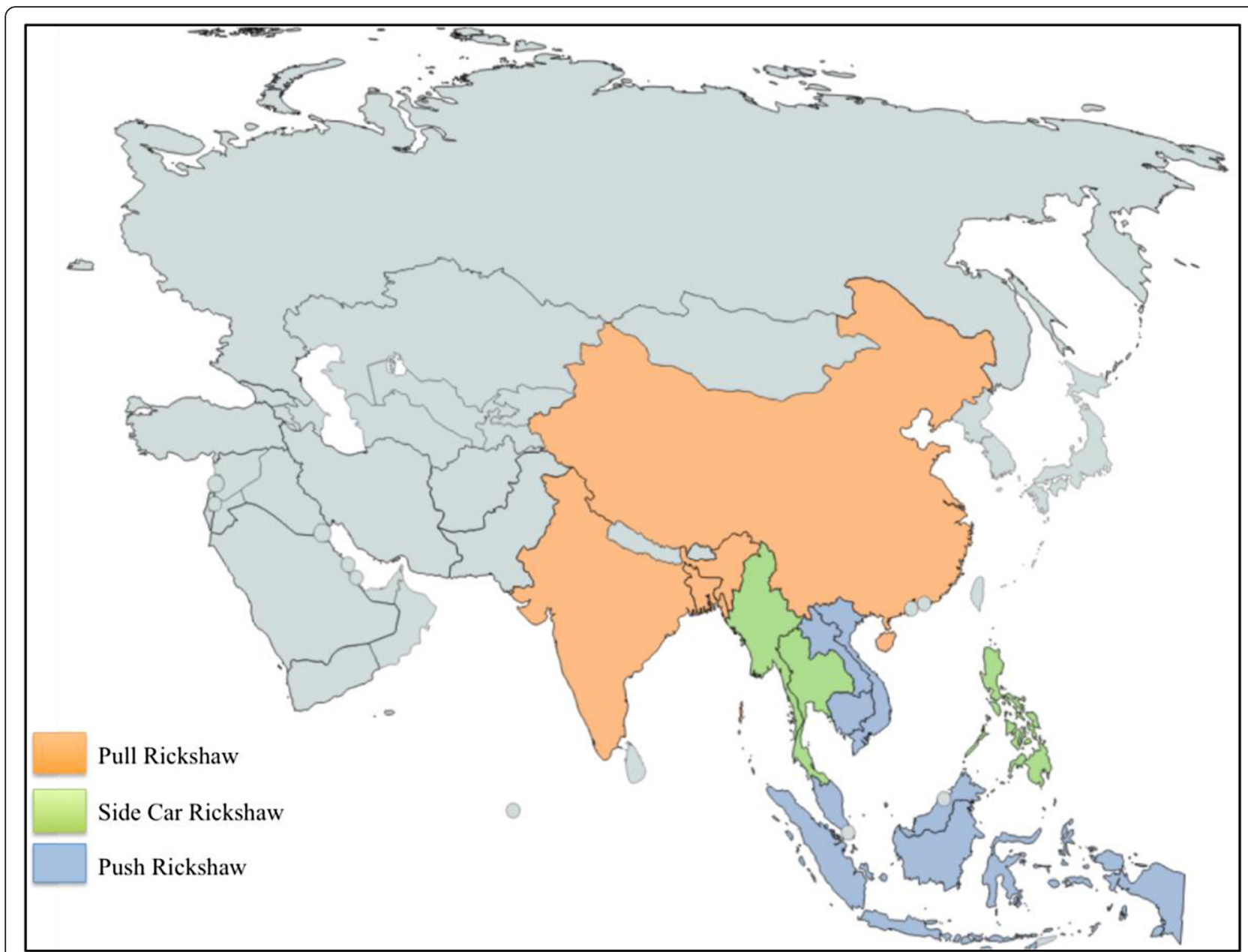

Fig. 1 Major types of rickshaws distributed across Asia

being environmentally friendly so as to leave a lowcarbon footprint. Technology development, governed by a non-exclusive technology transfer pact, impacts policy amendments and propagates strategic decision-making.

\section{Methods}

\section{Solar Electric Rickshaw}

The CSIR, India, is involved in developing low-cost technology keeping in mind the section of consumers who may not be able to afford the technology but, however, are in dire need of it. Among CSIR's flagship technologies is the solar-powered electric rickshaw, christened as the soleckshaw. As of 2013, there were 6,000,000 cycle rickshaw pullers in the capital city of Delhi alone (George 2013).

The drudgery involved in this profession is well documented. Rickshaw pullers suffer from poor nutrition and lack of preventive health care as well as the effects of pulling two to three times their weight. Injuries and chronic conditions are common, as are diseases such as tuberculosis that come from being exposed to air pollution and low nutrition leading to immunosuppression
(Majkowski 2008). Also, due to continuous exposure to pollution from motorised vehicle dust, etc., a large percentage of the rickshaw pullers get bronchial infections including tuberculosis after 3 to 4 years of work. They further transmit TB to children, whom they carry to school, resulting in hundreds of thousands of children being affected by TB. Hence, the demand for scientific intervention was created after observing the plight of rickshaw pullers. The lack of technology translation for social empowerment was one of the driving forces behind the development of the soleckshaw. CSIR's vision for the development of the soleckshaw was the following:

- High science for 800 million Indians at the bottom of the economic pyramid

- To reduce human drudgery through technology

- Mass popularisation of pollution-free vehicles

- Business model for designer, manufacturer, driver, VC

- Value engineering

- Affordable and sustainable 


\section{Design and efficiency}

The "soleckshaw" is christened from the words solar $(\mathrm{Sol})$, electric $(E)$ and rickshaw (Shaw) (Ashok Kumar Prasad et al. 2013). The design of the pedicab was such so as to increase the pulling capacity and improve the overall speed of the rickshaw while adhering to the Motor Vehicle Act of a battery-operated vehicle having a maximum capacity of $250 \mathrm{~W}$, also avoiding the need of obtaining driving licences and formal registration requirements. The overarching idea was to reduce the effort required in pedalling. As the motor capacity was limited, hence, a fully electric-assisted rickshaw design was not possible. A $36-\mathrm{V}$ motor installation assists the driver in pedalling. A brushless direct-current (BLDC) motor controller is at the centre of the handle. There are two modes in which the driver can operate the vehicle, the driver can first pedal and then turn the throttle to get assistance from the BLDC motor while pedalling, or first, the throttle can be used for minimal assistance from the motor and then begin pedalling; the first mode is said to be a more effective mechanism of driving the vehicle as this allows for a faster pickup, and the driver gets full assistance from the motor having to pedal with minimum effort. The motor, which weighs approximately $5 \mathrm{~kg}$, is powered by $36 \mathrm{~V}, 18$ Ah lead acid battery, which is charged by solar energy and can be charged at charging stations alternatively charged by grid power. A fully charged battery can cover a distance of 40-70 km at a variable speed with the maximum being $15 \mathrm{~km} / \mathrm{h}$. The battery may not fully remove the load of pedalling; however, it can reduce the effort required. The idea was to keep electricity usage to a minimum while charging the batteries, relying on solar energy, so as to keep the carbon footprint as low as possible (Narayanan and Dixit 2009). The technical specifications of the soleckshaw are given in Table 1 (Maji, Banerjee et al. 2010). Figure 2 shows the schematic diagram and first concept prototype of the soleckshaw.

Initially, the concept prototype was modified from an existing rickshaw, and the battery was to be charged from overhead solar panels or separate solar charging stations. However, owing to high costs of solar panels and their installation on the rickshaw, the design concept was restricted to the prototype phase and it was decided to rely upon solar charging stations for charging the batteries. Tying up with the Delhi Metro Rail Corporation (DMRC), a solar charging station was set up at the Chandini Chowk metro station in Delhi. The solar charging station is built with an array of photovoltaic cells. Another similar charging station was built at CMERI, Durgapur. The charging station has a capacity of $1950 \mathrm{~W}$ h. Figure 3 shows a solar charging station.

The Mark I version of the soleckshaw was designed, developed and prototyped by CMERI in a record time of 8 months. A functional prototype of the Mark I version was launched in Delhi in October 2008 for trial and test. The solar charging station for swapping batteries was set up at Chandini Chowk, Delhi, by the Central Electronics Limited, and the BLDC motor was developed by Crompton Greaves based on the specifications given by CMERI (Narayanan and Dixit 2009). The soleckshaw was launched at an initial price of around USD 670 (USD $1=$ INR 45 as of 1st January 2011); efforts were to reduce the price to approximately USD 450 so as to make it affordable to rickshaw pullers to directly own a rickshaw.

The soleckshaw was officially launched in October 2008, at Durgapur (West Bengal), Chandini Chowk (New Delhi) and Ghaziabad (Uttar Pradesh) with political patronage to get social acceptance. The soleckshaw has been successfully deployed in the cities of Ahmedabad, Chandigarh, Delhi, Durgapur, Faridabad, Gurgaon, Jaipur, Kolkata, Ranchi, Bokaro, Pune and Shillong (CSIR 2009).

\section{User innovation}

The first prototype of the solar electric rickshaw was designed with the passengers sitting with their back facing the rickshaw pullers; this was because the angle of inclination of the passenger is in the direction of the force applied thereby making it easier for the rickshaw puller to pedal. Upon field-testing, the feedback received was

Table 1 Specification of soleckshaw, developed by CSIR-CMERI

\begin{tabular}{ll}
\hline Power source & Solar and human \\
Type of drive & Motor-assisted pedal-driven (hybrid) \\
Solar panel & 3 SPVS (37 W at $12 \mathrm{~V}$ ) \\
Electric motor & BLDC-type hub motor (240 W, $36 \mathrm{~V}$ ) mounted on the front/rear wheel \\
Charging & Batteries may be charged from the solar charging station or from the main power supply source by battery swapping mechanism \\
Battery & 3 deep-discharge-type lead acid batteries \\
Transmission & Chain and sprocket drive \\
Brakes & Drum and shoe brake on both rear wheels. Brake on motor drum on the front wheel \\
Axle & Entire axle is mounted on a separate structure to ensure better alignment of both axles \\
Payload & 210 kg (driver and 2 passengers) \\
\hline
\end{tabular}




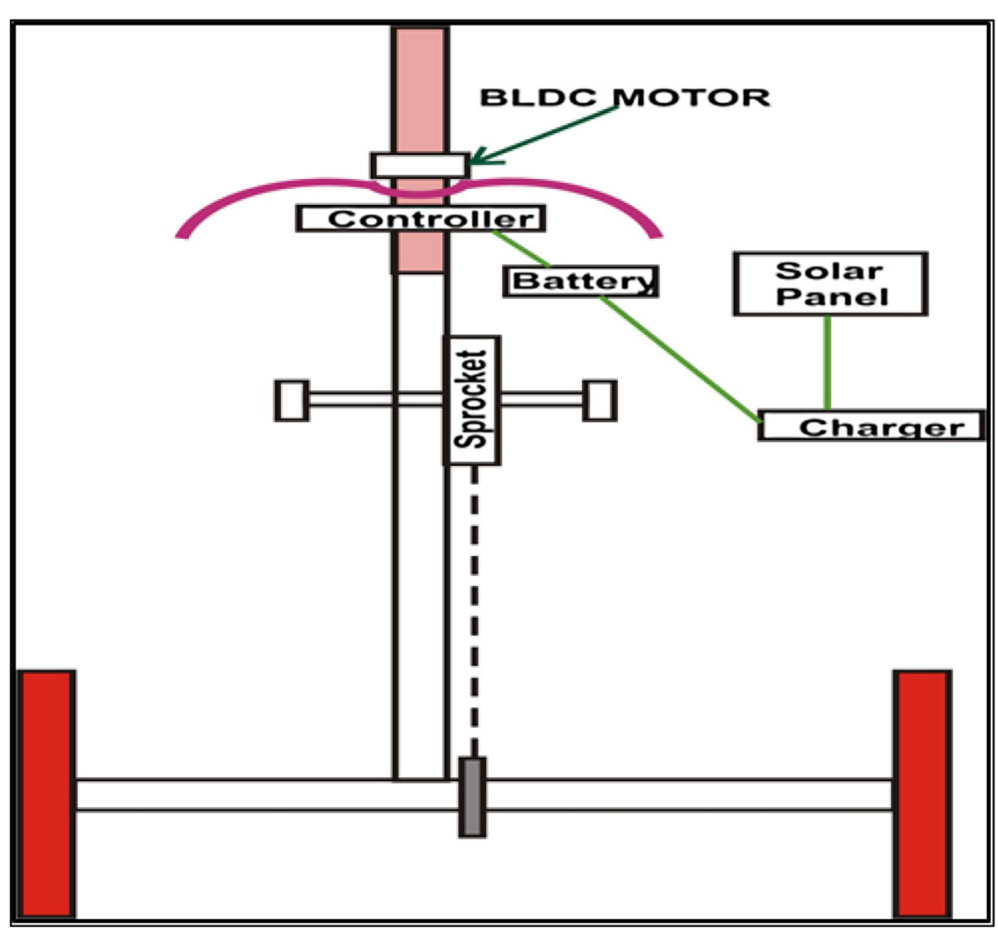

Fig. 2 Schematic diagram of the soleckshaw

that it makes it easier for the passengers to get off without paying the appropriate fee for the service; hence, the design had to be modified. The motor was initially placed near the front wheel; however, it was observed that during the monsoons, due to water logging, the motor became inaccessible; hence, in the subsequent prototypes, the motor was put below the seat and power was transmitted to the rear axle by chain drive. Figure 4 shows the first concept prototype of the soleckshaw. The important highlight of the user feedback was it proved that the best computer-aided design developed is not necessarily the best accepted design.

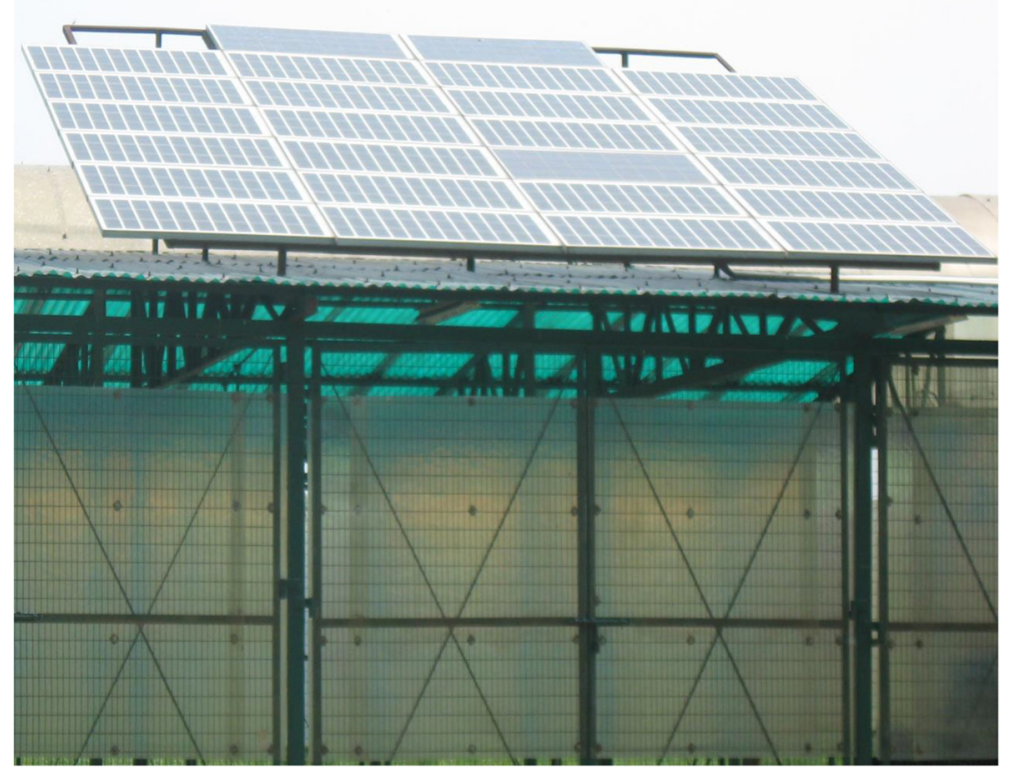

Fig. 3 A solar charging station at CSIR-CMERI, Durgapur 


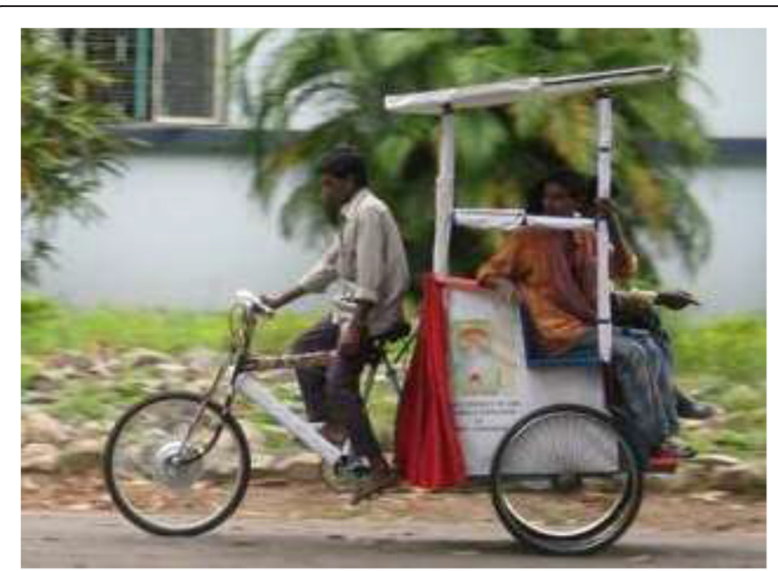

Fig. 4 First concept prototype of the soleckshaw

Based on rickshaw pullers' feedback, it was understood that the rickshaw width of 36 in. was too wide for narrow lanes of Chandini Chowk, where the total road width itself was 60-72 in.; hence, it would not be feasible to use the soleckshaw on these lanes. This feedback mechanism led to design development, and the size was brought down to 30 in. During product development, the role of the end user is pivotal. There were technological solutions that were demanded as the environmental conditions were tested. There are market forces that the scientific development team cannot predict. Hence, a disruption of the market occurs only when consumers are placed parallel in the hierarchy of the developers.

\section{Crowdsourcing the effort}

Although the original design and its intellectual property was developed and retained by CSIR, the effort was made so as to allow and encourage crowdsourcing the design improvement of the soleckshaw through non-exclusive licencing. The experience of the user in developing a newer prototype for design improvement and commercialisation was crowdsourced. As a result, large number of variants of the electric rickshaw came into the market through technology diffusion; this technology diffusion was propelled through open innovation whereby manufacturers could modify and improve the existing design thereby creating a large market share and allowing rapid proliferation.

With the new technology, a rickshaw puller could generate an income of approximately USD 330 per month as compared to approx USD 170 on a conventional rickshaw (Kumar 2011). The 1,000,000 electric rickshaws plying on the roads of the capital city of Delhi (Shukla, Dhar et al. 2014) have generated a revenue of nearly USD 40 million annually (assuming a monthly income of USD 330 per electric rickshaw). According to the Census of India, 2011, an average Indian household has a size of 4.9 (Nayak 2014) The average age of rickshaw pullers in Delhi is 27.5 years with most of them belonging to the age group of 19 to 40 (Kurosaki, Sawada.Y et al. 2007). In most of these households, the rickshaw puller is the sole bread winner; this highlights that each member now has access to USD 66 per month or USD 2.2 per day (considering equal income distribution per member) as opposed to USD 34 per month or USD 1.13 per day. The World Bank in 2015 put the poverty threshold at USD 1.9 a day; hence, nearly half a million lives are benefitted and have been empowered and marginally uplifted from poverty due to this technology intervention. Clearly highlighting technology empowerment can reduce human drudgery and mitigate poverty alleviation. Additional file 1: Annexure II shows a table of comparison between the conventional cycle rickshaw, soleckshaw and high-powered electric rickshaw. With the introduction of the electric rickshaw, rickshaw pullers have better access and can afford a nutritional diet so as to not be immuno-suppressed. The soleckshaw demonstrated that through simply connecting the technology dots, a technology innovation could lead to social empowerment.

To strengthen the reach of the soleckshaw, various intermediaries in the form of NGOs, RWAs and financial institutions, educational institutions, etc. were involved. NGOs such as Uthaan and Centre for Rural Development were rickshaw banks for the rickshaw pullers. Banking institutions provided subsidised loans. ISB ${ }^{1}$ and TERI ${ }^{2}$ were involved in developing a business plan and promoting the soleckshaw as part of an integrated movement. A Technology Demonstration Project (TDP) was implemented in association with the licensees. The outcome of the TDP was as shown in Table 2.

\section{Non-exclusive licencing}

The soleckshaw licence was distributed as a nonexclusive licence. The technology transfer agreement meant that CSIR could retain the intellectual property to exploit the scope of the technology and to further develop it as well as distribute the licence to as many licensors. In the initial agreement, the technology was transferred to Modular Machines, Faridabad and DEAN Systems, Kolkata. Thereafter, the technology was given to Stilam Automobiles, HBL Power Systems, Purti Green Technologies and Kinetic Motors. The list of licensees to whom the technology transfer of the soleckshaw was undertaken and the various major manufacturers of the various models of the electric rickshaws are given in Additional file 1: Annexure I. Through CSIR's policy intervention, the Central Excise Tariff Act allowed for a concessional rate of $4 \%$ excise duty on imported components of the battery-powered road vehicles (Department of Revenue 2010) thereby making it cheaper and easier to import components of the electric rickshaws manufactured in India. Figure 5 pictorially represents 
Table 2 Outcome of the Technology Demonstration Project (TDP)

\begin{tabular}{ll}
\hline TDP undertaken & Number of soleckshaws deployed \\
\hline With NGOs at different locations financed by the project & 83 \\
Deployed at various academic and R\&D organisations, financed by the project & 15 \\
Deployed at different locations, financed by other organisations & 169 \\
Total number of soleckshaws deployed at completion of TDP & 267 \\
\hline
\end{tabular}

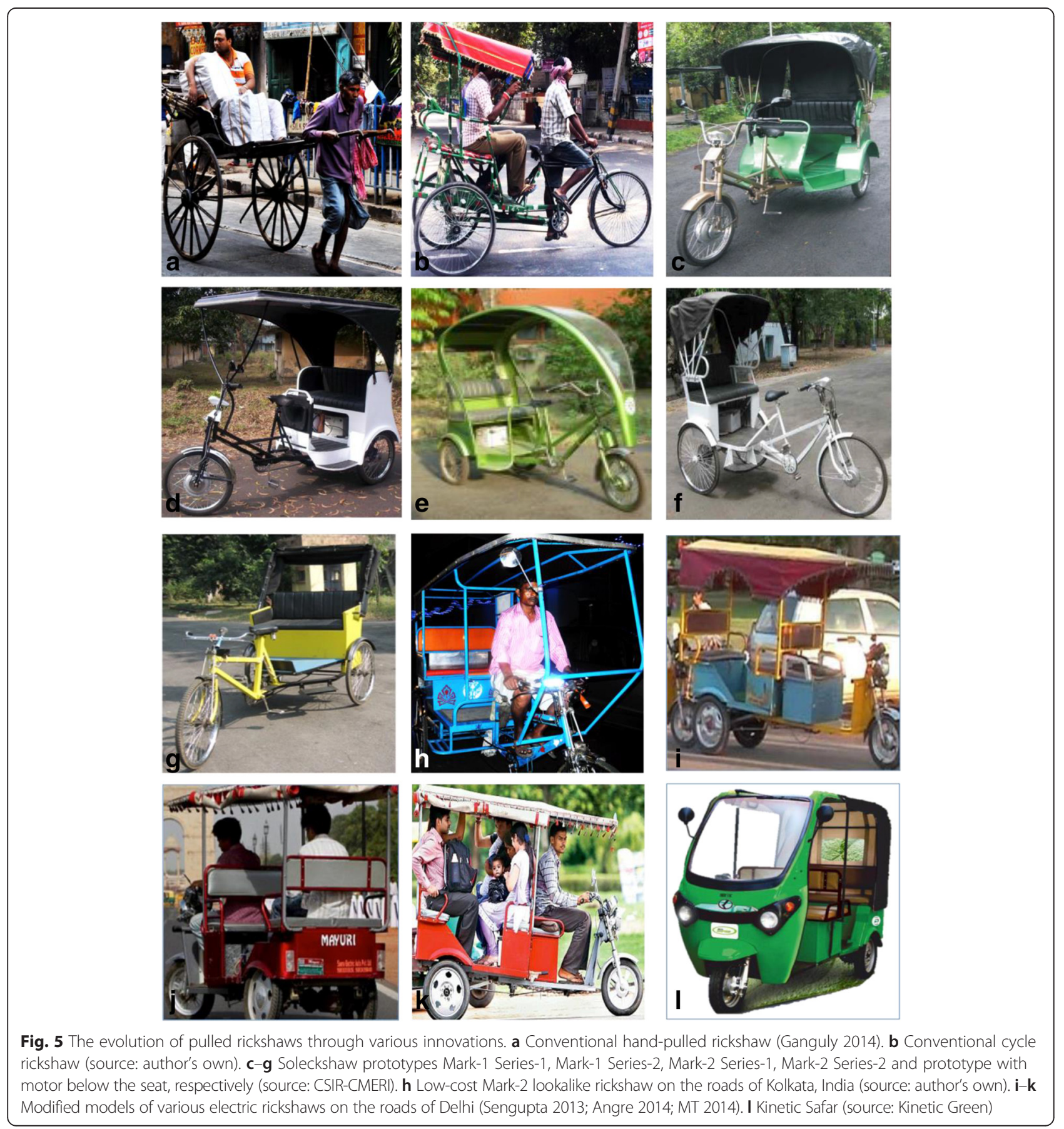


that conventional hand-pulled rickshaws gave way to the soleckshaw and further present-day electric rickshaws (including the Kinetic Safar) plying on the streets of India trace their design and concept to the soleckshaw prototypes.

\section{Results and Discussion \\ Commercialisation strategy: creation of new electric rickshaw market and policy amendment}

The soleckshaw technology was an important juncture in the public transport domain in India, as it allowed for the creation of a new market base of manufacturers. In the last 5 years, there has been a knowledge diffusion associated with motorising a conventional rickshaw leading to surprisingly the market acceptance of a higher value product in the form of electric rickshaws. This has been made possible with the intervention of the developers and the feedback of the users. This demanded a subsequent policy change.

The electric rickshaw market boomed; electric rickshaw parts are imported from China, assembled in India and then sold to consumers (Kartik Kumar 2014).

While no one Act governs non-motorised vehicles, motorised vehicles across India are under the Central Motor Vehicle (MV) Act, 1988. Chapter 1, Section XI of the Act states, "Battery Operated Vehicle' means a vehicle adapted for use upon roads and powered exclusively by an electric motor whose traction energy is supplied exclusively by traction battery installed in the vehicle: Provided that if the following conditions are verified and authorised by any testing agency specified in rule 126, the battery operated vehicle shall not be deemed to be a motor vehicle.

(i) the thirty minutes power of the motor is less than $0.25 \mathrm{~kW}$;

(ii)the maximum speed of the vehicle is less than $25 \mathrm{~km} / \mathrm{h}$."

CSIR ensured that they adhered to the 250-W stipulation of the Motor Vehicle Act, 1988, which categorised the soleckshaw as a "non-motor" vehicle whereby the soleckshaw pullers did not require a licence or registration. Being a low-powered rickshaw, the soleckshaw could pull only two persons, a maximum weight of $210 \mathrm{~kg}$, at the same time. However, the electric rickshaws plying presently are anywhere between 600 to $1000 \mathrm{~W}$ thereby allowing a capacity ride of four persons (Chakravartty 2014). This stirred the debate of bringing them under the "motor vehicle" category, issuing registrations and requiring a licence to ply the rickshaws; in such a scenario, the rickshaw pullers may not have the basic educational qualifications required to obtain a driver's licence.

As of 2015, it can be said that the electric rickshaw proliferation led to a policy intervention; the government of India recognising the employment being created through the electric rickshaw has decided to amend the Motor Vehicles Act of 1988, thereby bringing electric rickshaws under the legal framework.

\section{Disruption in the rickshaw market}

The Delhi State government has already issued licences to 1100 electric rickshaw drivers and is readying to grant 22,000 more licences. To assist the drivers, various camps were set up to facilitate issuing of drivers' licences and registration of the electric rickshaws. The central government will relax the eligibility criterion of " 8 th grade pass" for granting drivers' licences to original cycle rickshaw pullers to migrate to electric rickshaws (ENS 2015). As of August 2015, the Uttar Pradesh government has placed an order of nearly USD 60 million to procure and distribute 27,000 electric rickshaws, christened the Kinetic Safar, in a span of 12 months across the state. The project is being delivered by Kinetic Green, Pune, who were among the pioneer licensees of the soleckshaw.

\section{Conclusions}

The soleckshaw disrupted the rickshaw market by demonstrating that there is a need to change the existing cycle rickshaw model and allowing technology to intervene. Supported by a liberal technology transfer agreement with a nominal fee, the non-exclusive licencing and crowdsourcing of the design improvement effort allowed for the rapid proliferation of the electric rickshaw into the market, and since the assembly technology already existed, the commercialisation was easy. The project did so by adhering to standard rules and regulations. The endeavour shows how technology directs policy initiatives; the existing policy comes under scrutiny, and their redundancy gets tested when a market disruption occurs. The ability of decision makers to adapt simultaneously to the changing market would allow technologies to reach a wider consumer base and diffuse easily. This is an ideal example of how innovation ecosystem plays an important role in market acceptability of any product.

The development of the soleckshaw showed that in a social structure, identification of the problem is the prime task as it sets the development of a scientific idea in motion. Product development is an amalgamation of problem solving capacity and idea generation. The solar electric rickshaw was built on the fundamental principal that a product, which makes a social change by removing the drudgery of a rickshaw pullers life while being environmentally friendly and adhering to prescribed rules and regulations, could be created. The development brought together many different actors and forged various linkages. Innovation occurs when the existing knowledge is connected with existing technology to 
address a need in the market. Economic growth is a measure of development as well as the change in empowerment of economically weaker sections of the social structure. Scientific interventions in the form of knowledge creation and distribution, coupled with technology know-how, create a scope for improving the living conditions of people living at the bottom of the economic pyramid. An innovator nucleates an idea thereby creating a new disruptive market opening, the ecosystem of innovation from manufacturing to policy change and availability of financing eventually makes an innovation successful. This coordinated effort is the final stepping stone for social transformation and economic empowerment.

The case of the solar electric rickshaw proves that providing the market with a technology prototype by connecting the dots of earlier existing knowledge and technology to create a new technology has empowered rickshaw pullers. More so, the new market that has emerged in the form of electric rickshaws traces its roots back to the soleckshaw prototype. Leading a market change has spawned many micro-entrepreneurs in the form of manufacturers and distributors of electric rickshaws and finally led a large industry, the Kinetic Group, to make major capital investment to enter the market with high engineering standards (KG 2015). This is a unique example where IP-protected innovation of "Made in India" led to a large-scale production of "Make in India". The one lakh plus electric rickshaws plying on the Delhi roads and over an estimated half a million across the country need to be regularised, and the policy amendment to the Motor Vehicle Act, 1988, has been made. This is required in order to recognise the contribution of the rickshaw pullers to the state and national economy.

\section{Endnotes}

${ }^{1}$ www.isb.edu

${ }^{2}$ www.teriin.org

\section{Additional file}

Additional file 1: Annexures. (DOCX $84 \mathrm{~kb})$

\section{Competing interests}

The authors declare that they have no competing interests.

\section{Authors' contributions}

SKB conceptualised the project. SKB and NC wrote the article. Both authors read and approved the final manuscript.

\section{Acknowledgements}

The authors acknowledge the technical input and personal interviews of Dr. Palash Maji and Dr. Amit Banerjee at CSIR-CMERI. The authors acknowledge the personal communication of Ms. Sulajja Firodia of Kinetic Green. SKB acknowledges the technical advice and encouragement of Dr. Sumantran and Dr. Arun Firodia during the early stage of concept development of the soleckshaw. SKB also acknowledges the contribution of Dr. Gopal Sinha and Dr. Gautam Biswas, directors of CSIR-CMERI, for supporting an idea of soleckshaw. The authors are grateful to the Department of Science and Technology (DST), India, for the J. C. Bose National Fellowship awarded to SKB and the Council of Scientific and Industrial Research (CSIR), India, for providing financial support to NC (grant no: P-81-101).

Received: 30 June 2015 Accepted: 9 December 2015

Published online: 22 December 2015

\section{References}

Angre, K. (2014). Government upstages AAP, lifts ban on e-rickshaws in Delhi. from http://www.ndtv.com/india-news/government-upstages-aap-lifts-banon-e-rickshaws-in-delhi-579139. access on 15th December 2015.

Chakravartty, A. (2014). Last mile chaos. India: Down To Earth.

Christensen, C. (1997). The innovator's dilemma: when new technologies cause great firms to fail. Boston: Harvard Business School Press.

CSIR. (2009). Soleckshaw - solar powered rickshaw. from http://www.csir.res.in/ csir/external/heads/aboutcsir/announcements/ngo/csir800_soleckshaw.pdf. access on 15th December 2015.

Department of Revenue, M. (2010). The Central Excise Act. M. o. Finance. India: Government of India.

Edgerton, D. (2007). The shock of the old: technology and global history since 1900. Oxford University Press.

ENS, E. N. S. (2015). Green flag to 22,000 e-rickshaws. India: The Indian Express.

Ganguly, B. (2014). Hand-pulled rickshaw - Surya Sen Street -Kolkatta: Wikimedia Commons. 2015, from https://commons.wikimedia.org/wiki/File:Hand-pulled_ Rickshaw_-_Surya_Sen_Street_-_Kolkata_2014-01-01_1773.JPG. access on 15th December 2015 .

George, P. (2013). Pedaling for bread: rickshaw pullers of Delhi struggle for a living. Retrieved 23-04, 2014, from http://www.ritimo.org/article4819.html. access on 15th December 2015.

Hang, C., Chen, J., \& Subramian, A. M. (2010). Developing disruptive products for emerging economies: lessons from Asian cases. Engineering Management Review, IEEE, 41(4), 119-126.

Jim, W. (2011). The Singapore rickshaw pullers: the social organization of a coolie occupation, 1880-1940. Journal of Southeast Asian Studies 16

Kanwar, P. (2003). Imperial Simla: the political culture of the Raj. Oxford University Press.

Kartik Kumar, S. G. (2014). It's cheaper: dealers import rickshaw parts from China, assemble them here. The Indian Express. http://indianexpress.com/article/cities/ delhi/its-cheaper-dealers-import-rickshaw-parts-from-china-assemble-them-here/. access on 15th December 2015.

KG, K. G. (2015). About Kinetic Green and Safar. India: Kinetic Engineering Limited.

Kim, W. and R. Mauborgne (1999). Strategy, value innovation, and the knowledge economy. Sloan management review. Massachusetts Institute of Technology (USA).

Kumar, R. (2011). Soleckshaw - an initiative to explore S\&T infrastructure for inclusive growth. New Delhi: 25th Skoch Summit.

Kurosaki, T., Sawada.Y, A. Banerji and S. N. Mishra (2007). Rural-urban migration and urban poverty: socio-economic profiles of rickshaw pullers and ownercontractors in North-East Delhi. CIRJE Discussion Paper. University of Tokyo

Maji, P., Banerjee, P., Banerjee, A. J., \& Maity, S. (2010). Electric motor-assisted pedal-driven tricycle. Int. J. Electric and Hybrid Vehicles, 2(3), 202-210.

Majkowski, N. (2008). Kolkata rickshaws: who are the rickshaw wallahs? Retrieved 23-04, 2014, from http://ngm.nationalgeographic.com/geopedia/Kolkata_Rickshaws. access on 15th December 2015.

Motooka, H. (2008). A study on the current role of cycle rickshaw in Southeast Asia.

MT, M. T. (2014). Transport department to draft policy on Delhi's e-rickshaw trade, from http://www.dailymail.co.uk/indiahome/indianews/article-2628443/ Transport-department-draft-policy-Delhis-e-rickshaw-trade.html. access on 15th December 2015

Narayanan, S. and V. Dixit (2009). Solar powered rickshaw. MIT Technology Review. Massachusetts: Jason Pontin.

Nayak, D. K. (2014). Changing household size in India: an inter-state comparison. Transactions. India: Institute of Indian Geographers.

Prahalad, C. (2005). Fortune at the bottom of the pyramid: eradicating poverty through profit. USA: Wharton School Publishing.

Prasad, A. K., Banerjee, A. J., Maji, P., Padhi, R. K. (2013). Soleckshaw, an alternate solution to green transport. Elixir Mechanical Engineering, 55, 13120-13123.

Rahman, M., G. D'Este and J. Bunker (2008). Problems and prospects of non-motorized public transport integration in developing cities. The 30th Conference of the 
Australian Institutes of Transport Research. Perth, Western Australia: Eastern Asia Society for Transportation Studies (EASTS).

Rahman, M., G. D'Este and J. Bunker (2009). Is there a future for non-motorized public transport in Asia? 8th International Conference of the Eastern Asia Society for Transportation Studies Surabaya, Indonesia.

Rhaman, M. (2013). Electric motorized rickshaw can preserve the inhumanity rickshaw labor in Bangladesh without interrupt power system. Dhaka, Bangladesh: 4th Global Engineering, Science and Technology Conference.

Sengupta, S. (2013). Transport department to setup charging stations for erickshaws. from http://www.dailypioneer.com/city/transport-department-toset-up-charging-stations-for-e-rickshaws.html. access on 15th December 2015.

Shukla, P. R., Dhar, S., Pathak, M., \& Bhaskar, K. (2014). Electric vehicle scenarios and a roadmap for India. Promoting low carbon transport in India. Ahmedabad: Indian Institute of Management.

Singh, M., A. Gambhir and J. Dasgupta (2011). Innovation in India: affordable innovations. Global Innovation Index. INSEAD.

Yu, D. and C. Hang (2010). A reflective review of disruptive innovation theory. International Journal of Management Reviews, 12(4), 435-452.

\section{Submit your manuscript to a SpringerOpen ${ }^{\mathcal{O}}$ journal and benefit from:}

- Convenient online submission

Rigorous peer review

- Immediate publication on acceptance

- Open access: articles freely available online

- High visibility within the field

- Retaining the copyright to your article

Submit your next manuscript at $\gg$ springeropen.com 